\title{
Sistem Pemantauan dan Pengendalian Debit Fluida Berbasis Arduino dan Website
}

\section{(Monitoring and Controling Fluid System Based on Arduino and Website)}

\author{
Noviana Widyaningrum ${ }^{1}$, Unan Yusmaniar Oktiawati ${ }^{2}$
}

\begin{abstract}
IoT can combine hardware and software for communication between them. The application of this system can be done on a solenoid valve to regulate the flow via online, which can be varied based on current temperature. The fluid flows are validated with a flow meter sensor that sends data to a server to decide whether the flows need to be added to the furnace or not. There is a database server that stores data in cloud from sensors so that the system can run realtime. The system is displayed on a website with dashboard display regarding the flow and the condition of the valves in realtime. In testing, black box testing is used to make more use of functional things in the system designed for the convenience of users of fluid flow monitoring and control, based on the appearance of the website used, the functions available, the results of the sensors provided, and the data transmission process that is running. Furthermore, the system can show that the function of the hardware or website to monitor and control fluid discharge has been running well and can be used by users easily and beneficially.
\end{abstract}

Intisari-IoT merupakan perpaduan antara perangkat keras dan perangkat lunak untuk melakukan komunikasi antara keduanya. Penerapan sistem ini dapat dilakukan pada katup solenoid untuk mengatur aliran secara daring yang akan disesuaikan dengan suhu yang naik atau turun. Validasi debit fluida yang dihasilkan ini dibaca oleh sensor flow meter yang akan mengirim data ke server, baik terjadi penambahan aliran yang akan menuju ke tungku atau tidak. Terdapat server basis data yang menyimpan data pada cloud dari sensor, sehingga sistem dapat berjalan secara daring. Sistem ditampilkan pada website dengan dashboard yang meliputi nilai debit aliran dan kondisi katup secara real-time. Dalam pengujiannya, blackbox testing digunakan agar lebih memanfaatkan hal fungsional pada sistem yang dirancang demi kenyamanan pengguna terhadap pemantauan dan pengendalian debit fluida berdasarkan tampilan website yang digunakan, fungsi yang ada, hasil dari sensor yang diberikan, serta proses transmisi data yang berjalan. Sistem dapat menunjukkan bahwa fungsi pada perangkat keras maupun website untuk memantau maupun mengendalikan debit fluida telah berjalan dengan baik dan dapat digunakan oleh pengguna secara mudah dan bermanfaat.

Kata Kunci-Black Box Testing, Website, Katup Solenoid, Sensor Flow Meter.

\section{Pendahuluan}

Saat ini, tingkat efisiensi dan kemudahan diterapkan merupakan tolok ukur dalam penerapan teknologi yang

1,2 Departemen Teknik Elektro dan Informatika, Sekolah Vokasi, Universitas Gadjah Mada, Jl. Yacaranda Sekip IV, Yogyakarta, 55281 INDONESIA (tlp: (0274) 6491302, 56111; fax: (0274) 542908; e-mail: ${ }^{1}$ noviana.widyaningrum@mail.ugm.ac.id; ${ }^{2}$ unan_yusmaniar@ugm.ac.id) berkembang dengan tujuan untuk memangkas waktu dan kegiatan manusia secara efektif. Salah satu bentuk teknologi yang berkaitan erat dengan tingkat produktivitas manusia adalah Internet of Things atau biasa disebut dengan IoT. IoT merupakan komunikasi data yang terjadi antara objek fisik dengan objek yang bersifat maya pada suatu jaringan global [1]. Implementasi alat IoT dapat diterapkan di berbagai sektor, seperti rumah tangga, pertanian, perkebunan, perairan, bahkan industri. Hal ini dikarenakan adanya mikroprosesor yang berperan sebagai pemroses utama dari sensor yang diterapkan dan dapat terhubung ke internet, sehingga hasil dari pembacaan sensor yang didapatkan dapat dipantau dan dianalisis secara otomatis serta real-time dengan disambungkan ke berbagai platform, seperti web, aplikasi Android, dan Telegram. IoT semakin berkembang untuk membantu pekerjaan manusia yang berhubungan dengan teknologi dengan mengintegrasikan beberapa perangkat, seperti sensor, Radio Frequency Identification (RFID), wireless sensor network, dan sebagainya yang dimungkinkan, agar mudah untuk berkomunikasi melalui koneksi internet [2]. IoT didefinisikan sebagai bentuk kegiatan yang dilakukan dengan menggunakan media akses sehingga segala bentuk aktivitas menjadi mudah, juga dapat dihubungkan dengan cloud yang akan membuat sistem IoT menjadi semakin efisien. Tidak hanya itu, dengan disimpan dalam cloud ini, pengguna menjadi mudah untuk mengambil data kapan saja dan di mana saja, serta keamanannya pun terjamin. Akan tetapi, untuk menjalankan IoT yang terintegrasi cloud computing, akses bandwidth yang cukup serta penyimpanan yang besar harus terpenuhi [3].

Dari tinjauan tersebut, digunakan mikroprosesor Arduino Uno dengan dasar perangkat yang mudah didapatkan dengan harga terjangkau dan kompatibel untuk perancangan sistem yang berbasis IoT dari yang sederhana hingga kompleks sekalipun. Arduino Uno mampu melakukan monitoring atau pemantauan di dalam maupun luar ruangan yang juga terhubung dengan jaringan lokal maupun publik menggunakan ethernet shield atau Wi-Fi shield dan disimpan dalam penyimpanan lokal maupun server secara real-time.

Makalah ini membahas pemantauan aliran debit bahan bakar berbasis Arduino dan website. Penelitian sebelumnya yang mirip telah dilakukan, yaitu sistem pengendalian suhu pada tungku bakar yang dapat dijalankan otomatis menggunakan metode kontroler PID dan hand tunning [4]. Keuntungan dari penerapan metode ini adalah respons yang halus dan cepat yang dibuktikan dengan kenaikan suhu dengan acuan laju pembakaran yang telah ditentukan memiliki rata-rata kesalahan sebesar $1,877 \%$. Kemudian kontroler PID berbasis Arduino menghasilkan respons sesuai yang direncanakan dan dapat 


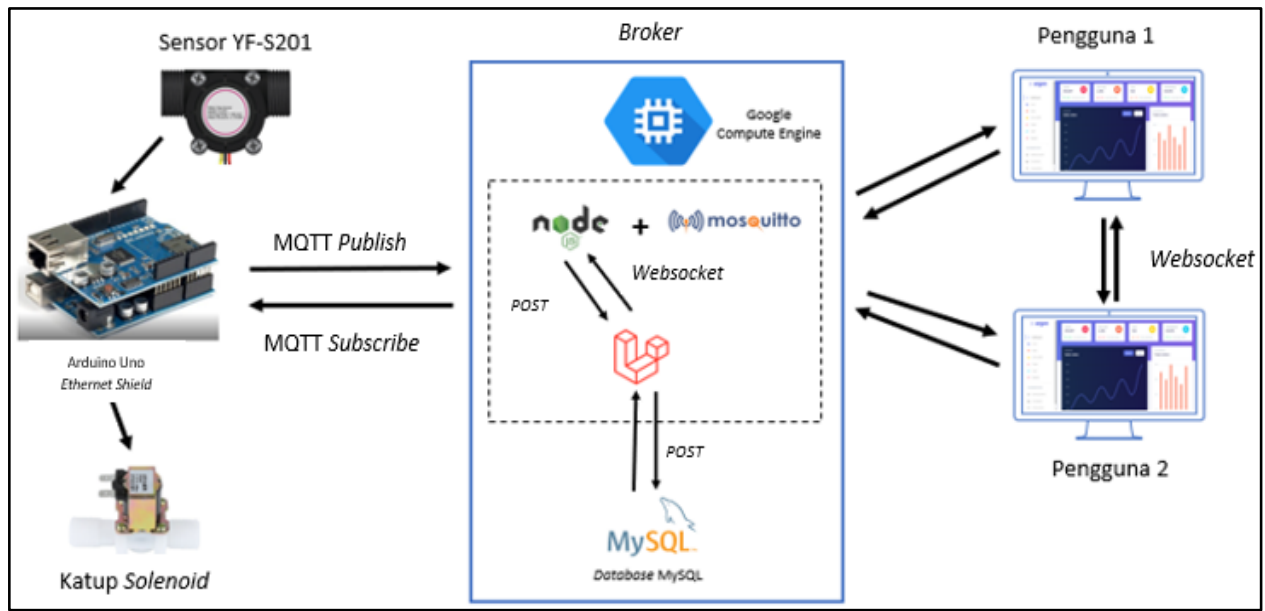

Gbr. 1 Topologi sistem.

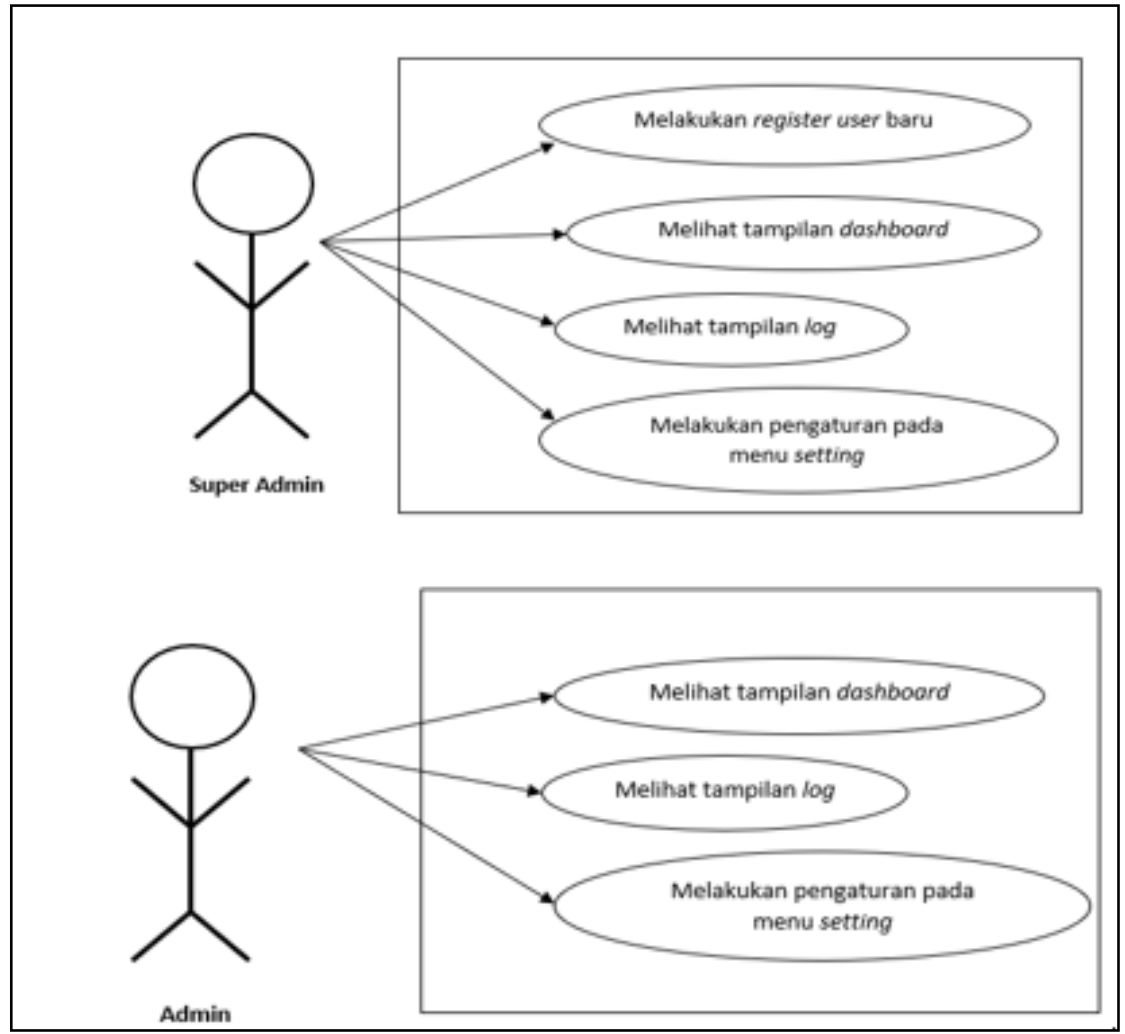

Gbr. 2 Use case diagram.

diaplikasikan pada sistem pengendalian suhu untuk mencapai laju pembakaran yang diinginkan. Komponen yang digunakan adalah Arduino Uno Rev3, sensor suhu PT100, dan motor servo [4].

Adanya pemantauan objek berupa debit fluida yang menuju ke tungku menjadi sebuah solusi untuk mengefektifkan kinerja manusia. Sistem bekerja dengan mengambil data aliran dan melakukan perhitungan debit yang didapatkan secara real-time terhadap perubahan yang sewaktu-waktu dapat terjadi. Oleh karena itu, diperlukan aksi yang cepat tanggap untuk mengatasi hal tersebut agar tidak sampai menimbulkan kelebihan maupun kekurangan volume fluida pada tungku. Platform yang digunakan sebagai server adalah Google Compute Engine yang kompatibel dengan perangkat IoT serta protokol MQTT. Google Compute Engine termasuk sebagai infrastructure-as-aservice sebagai penyedia sumber daya komputasi virtual seperti CPU, penyimpanan (storage), dan komponen jaringan, sehingga memudahkan pengguna melakukan integrasi sistem, baik dengan perangkat keras maupun perangkat lunak [5]. Ini juga dipilih karena dapat menghasilkan alamat IP publik secara otomatis dan menggunakan teknologi serverless, sehingga mudah dilakukan konfigurasi kebutuhan server yang diinginkan tanpa harus memikirkan perawatan fisik server.

Makalah ini menawarkan solusi dengan melakukan pemantauan pada fluida maupun pengendalian secara jarak jauh terhadap perangkat yang digunakan. Arduino Uno 
TABEL I

SKENARIO BLACKBOX TESTING

\begin{tabular}{|l|l|}
\hline \multicolumn{1}{|c|}{ Data Masukan } & \multicolumn{1}{|c|}{ Skenario Pengujian } \\
\hline $\begin{array}{l}\text { Sensor flow meter } \\
\text { YF-S201 }\end{array}$ & $\begin{array}{l}\text { Pembacaan data debit fluida yang } \\
\text { mengalir pada pipa }\end{array}$ \\
\hline Katup solenoid & Pembuka katup pada pipa tambahan \\
\hline Ethernet shield & Penerima jaringan internet \\
\hline Login & Melakukan login masuk ke website \\
\hline Log & $\begin{array}{l}\text { Melihat riwayat aktivitas pemantauan dan } \\
\text { pengendalian yang dilakukan di website }\end{array}$ \\
\hline Beranda & $\begin{array}{l}\text { Menampilkan grafik pembacaan sensor } \\
\text { secara real-time }\end{array}$ \\
\hline Pengaturan & $\begin{array}{l}\text { Mengatur katup solenoid pada pipa } \\
\text { tambahan dengan mendapatkan data suhu }\end{array}$ \\
\hline Notifikasi & $\begin{array}{l}\text { Pemberitahuan apabila katup telah } \\
\text { terbuka maupun tertutup }\end{array}$ \\
\hline
\end{tabular}

TABEL II

BLACKBOX TESTING PADA KATUP SOLENOID

\begin{tabular}{|l|l|l|l|}
\hline Butir Uji & \multicolumn{1}{|c|}{$\begin{array}{c}\text { Hasil yang } \\
\text { Diharapkan }\end{array}$} & $\begin{array}{c}\text { Hasil } \\
\text { Sebenarnya }\end{array}$ & Kesimpulan \\
\hline Status ON & $\begin{array}{l}\text { Katup solenoid } \\
\text { dapat membuka } \\
\text { penuh ketika } \\
\text { diberikan tegangan } \\
\text { yakni HIGH pada } \\
\text { mikrokontroler. }\end{array}$ & $\begin{array}{l}\text { Katup } \\
\text { solenoid } \\
\text { terbuka } \\
\text { penuh. }\end{array}$ & Berhasil \\
& $\begin{array}{l}\text { Katup solenoid } \\
\text { dapat menutup } \\
\text { ketika tegangan } \\
\text { OFF }\end{array}$ & $\begin{array}{l}\text { Katup } \\
\text { solenoid } \\
\text { tertutup } \\
\text { penuh. }\end{array}$ & \\
& LOW. & Berhasil \\
& & & \\
\hline
\end{tabular}

diimplementasikan sebagai mikroprosesor yang akan terintegrasi dengan website.

\section{Pemantauan DAN PENGENDAlian}

\section{A. Perancangan Sistem}

Sensor YF-S201 sebagai sensor flow meter berfungsi mendeteksi laju aliran yang bersifat fluida yang ditunjang juga dengan penyelubung sensor dengan bahan plastik [6]. Hasil pembacaan sensor kemudian dikirimkan ke server basis data yang berupa cloud computing milik Google dibidang IoT, yaitu Google Compute Engine, kemudian hasilnya ditampilkan dengan laman web di sisi end-user. Selain dapat memantau debit, web juga dapat mengontrol debit yang masuk dengan mengaktifkan pipa tambahan atau tidak, memberikan notifikasi apabila debit terlalu deras, dan terdapat log. Pada pipa tambahan yang digunakan ini terdapat katup solenoid yang memiliki tegangan $12 \mathrm{~V}$ dengan kondisi awal tertutup, tetapi dapat terbuka bila sudah dialiri arus listrik. Tipe katup solenoid yang digunakan adalah yang berbahan plastik yang dapat digunakan untuk zat cair [7]. Protokol yang digunakan untuk pengiriman data adalah protokol MQTT yang bekerja berbasis suatu topik dengan mekanisme publisher dan subscriber yang berjalan dengan sederhana dan ringan untuk meminimalkan penggunaan bandwidth jaringan, kebutuhan sumber daya, dan memastikan pengiriman data dengan tepat [8]. Dalam hal ini,
TABEL III

BLACKBOX TESTING PADA SENSOR YF-S201

\begin{tabular}{|c|c|c|c|}
\hline Butir Uji & $\begin{array}{c}\text { Hasil yang } \\
\text { Diharapkan }\end{array}$ & $\begin{array}{c}\text { Hasil } \\
\text { Sebenarnya }\end{array}$ & Kesimpulan \\
\hline $\begin{array}{l}\text { Pembacaan } \\
\text { data debit }\end{array}$ & $\begin{array}{l}\text { Sensor YF- } \\
\text { S201 dapat } \\
\text { membaca } \\
\text { debit yang } \\
\text { melewati } \\
\text { pipa dari } \\
\text { tangki ke } \\
\text { tungku. }\end{array}$ & $\begin{array}{l}\text { Sensor YF- } \\
\text { S201 } \\
\text { membaca } \\
\text { debit dalam } \\
\text { satuan } \\
\text { ml/detik yang } \\
\text { melewati pipa } \\
\text { dari tangki ke } \\
\text { tungku. }\end{array}$ & Berhasil \\
\hline $\begin{array}{l}\text { Pengiriman } \\
\text { data ke web } \\
\text { dan basis data }\end{array}$ & $\begin{array}{l}\text { Data dari } \\
\text { sensor YF- } \\
\text { S201 akan } \\
\text { dikirim ke } \\
\text { website } \\
\text { dengan } \\
\text { protokol } \\
\text { MQTT dan } \\
\text { ke basis data } \\
\text { dengan } \\
\text { protokol } \\
\text { HTTP. }\end{array}$ & $\begin{array}{l}\text { Sesuai } \\
\text { harapan } \\
\text { sensor dapat } \\
\text { mengirimkan } \\
\text { data. }\end{array}$ & Berhasil \\
\hline
\end{tabular}

BLACKBOX TESTING PADA ETHERNET SHIELD

\begin{tabular}{|l|l|l|l|}
\hline \multicolumn{1}{|c|}{ Butir Uji } & $\begin{array}{c}\text { Hasil yang } \\
\text { Diharapkan }\end{array}$ & $\begin{array}{c}\text { Hasil } \\
\text { Sebenarnya }\end{array}$ & Kesimpulan \\
\hline $\begin{array}{l}\text { Mendapat } \\
\text { alamat IP }\end{array}$ & $\begin{array}{l}\text { Ethernet shield } \\
\text { mendapatkan } \\
\text { alamat IP. }\end{array}$ & $\begin{array}{l}\text { Ethernet shield } \\
\text { mendapatkan } \\
\text { alamat IP. }\end{array}$ & Berhasil \\
\hline $\begin{array}{l}\text { Terhubung } \\
\text { ke internet }\end{array}$ & $\begin{array}{l}\text { Ethernet shield } \\
\text { terkoneksi } \\
\text { dengan }\end{array}$ & $\begin{array}{l}\text { Ethernet shield } \\
\text { terkoneksi } \\
\text { dengan internet } \\
\text { sehingga dapat }\end{array}$ & Berhasil \\
& internet. & $\begin{array}{l}\text { membuka } \\
\text { website dan } \\
\end{array}$ & mengirimkan \\
& & data untuk & \\
& & & \\
& &
\end{tabular}

Arduino adalah publisher dan website sebagai subscriber. Alur dari transmisi data diperlihatkan pada Gbr. 1.

\section{B. Use Case Diagram}

Use case digunakan untuk memperjelas pembagian tugas atau fungsi masing-masing pengguna terhadap perancangan sistem yang dibuat. Use case diagram divisualisasikan pada Gbr. 2. Dari use case tersebut dapat dijelaskan bahwa terdapat dua pengguna yang diberi akses untuk masuk ke sistem, yakni Super Admin dan Admin, dengan masing-masing fungsi seperti yang tampak pada gambar. Super Admin diperuntukkan bagi atasan atau pemimpin proyek sistem pemantauan dan pengendalian debit fluida, sehingga dapat melakukan segala fungsi, termasuk melakukan penambahan pengguna. Sementara itu, Admin adalah orang yang melakukan tugas sesuai arahan Super Admin dan diberi wewenang untuk melakukan pemantauan dan pengendalian terhadap sistem yang dirancang. 
TABEL V

BLACKBOX TESTING MENU LOGIN

\begin{tabular}{|c|c|c|c|}
\hline Butir Uji & $\begin{array}{c}\text { Hasil yang } \\
\text { Diharapkan }\end{array}$ & $\begin{array}{c}\text { Hasil } \\
\text { Sebenarnya }\end{array}$ & Kesimpulan \\
\hline $\begin{array}{l}\text { Memasukkan } \\
\text { username dan } \\
\text { password } \\
\text { yang tidak } \\
\text { terdaftar }\end{array}$ & $\begin{array}{l}\text { Sistem } \\
\text { memberitahu } \\
\text { bahwa } \\
\text { kombinasi } \\
\text { salah }\end{array}$ & $\begin{array}{l}\text { Muncul popup } \\
\text { notifikasi } \\
\text { username and } \\
\text { password } \\
\text { combination } \\
\text { invalid }\end{array}$ & Berhasil \\
\hline $\begin{array}{l}\text { Memasukkan } \\
\text { username saja }\end{array}$ & $\begin{array}{l}\text { Terdapat } \\
\text { peringatan } \\
\text { untuk } \\
\text { memasukkan } \\
\text { password }\end{array}$ & $\begin{array}{l}\text { Terdapat } \\
\text { peringatan di } \\
\text { bawah kolom } \\
\text { password } \\
\text { "Harap } \\
\text { masukkan } \\
\text { Password } \\
\text { Anda!” }\end{array}$ & Berhasil \\
\hline $\begin{array}{l}\text { Memasukkan } \\
\text { password saja }\end{array}$ & $\begin{array}{l}\text { Terdapat } \\
\text { peringatan } \\
\text { untuk } \\
\text { memasukkan } \\
\text { username }\end{array}$ & $\begin{array}{l}\text { Terdapat } \\
\text { peringatan di } \\
\text { bawah kolom } \\
\text { username } \\
\text { "Harap } \\
\text { masukkan } \\
\text { Username } \\
\text { Anda!” }\end{array}$ & Berhasil \\
\hline $\begin{array}{l}\text { Memasukkan } \\
\text { username } \\
\text { dengan benar } \\
\text { namun } \\
\text { password } \\
\text { salah }\end{array}$ & $\begin{array}{l}\text { Sistem } \\
\text { memberitahu } \\
\text { bahwa } \\
\text { kombinasi } \\
\text { salah }\end{array}$ & $\begin{array}{l}\text { Muncul popup } \\
\text { notifikasi } \\
\text { username and } \\
\text { password } \\
\text { combination } \\
\text { invalid }\end{array}$ & Berhasil \\
\hline $\begin{array}{l}\text { Memasukkan } \\
\text { password } \\
\text { dengan benar } \\
\text { namun } \\
\text { username } \\
\text { salah }\end{array}$ & $\begin{array}{l}\text { Sistem } \\
\text { memberitahu } \\
\text { bahwa } \\
\text { kombinasi } \\
\text { salah }\end{array}$ & $\begin{array}{l}\text { Muncul popup } \\
\text { notifikasi } \\
\text { username and } \\
\text { password } \\
\text { combination } \\
\text { invalid }\end{array}$ & Berhasil \\
\hline $\begin{array}{l}\text { Memasukkan } \\
\text { username dan } \\
\text { password } \\
\text { dengan benar }\end{array}$ & $\begin{array}{l}\text { Dapat masuk } \\
\text { ke sistem dan } \\
\text { menampilkan } \\
\text { menu Beranda }\end{array}$ & $\begin{array}{l}\text { Berhasil } \\
\text { masuk ke } \\
\text { sistem dan } \\
\text { menampilkan } \\
\text { menu Beranda }\end{array}$ & Berhasil \\
\hline
\end{tabular}

\section{Pengambilan Data}

Pengujian yang digunakan adalah blackbox testing, yang merupakan salah satu metode pengujian sistem yang menggunakan blackbox sebagai teknik untuk pengujian yang berfokus pada hasil keluaran pada program dengan memberi nilai masukan dan menemukan kesalahan melalui lima parameter, yaitu fungsi, antarmuka, struktur data, kinerja aplikasi, maupun inisialisasi dan terminasi [9]. Selain itu, pengujian ini juga dipilih pada bagian pengujian sistem yang dibagi menjadi dua jenis, yakni fungsional dan nonfungsional. Namun, makalah ini melakukan pengujian fungsional pada aspek smoke testing dengan tujuan menentukan sistem dapat diuji atau tidak [10], baik perangkat keras maupun perangkat lunak, yang diambil datanya dengan kuesioner ke beberapa orang untuk mencoba website menggunakan "guest mode” dan ada yang bertindak sebagai Super Admin untuk mencoba
TABEL VI

BLACKBOX TESTING MENU BERANDA

\begin{tabular}{|l|l|l|l|}
\hline \multicolumn{1}{|c|}{ Butir Uji } & $\begin{array}{c}\text { Hasil yang } \\
\text { Diharapkan }\end{array}$ & $\begin{array}{c}\text { Hasil } \\
\text { Sebenarnya }\end{array}$ & Kesimpulan \\
\hline Grafik & Menampilkan & Menampilkan & Berhasil \\
pemantauan & grafik & $\begin{array}{l}\text { grafik dan } \\
\text { status debit, } \\
\end{array}$ & \\
& pemantauan & \\
& debit fluida. & $\begin{array}{l}\text { suhundisi } \\
\text { katup secara } \\
\text { real-time. }\end{array}$ & \\
& & \\
\hline
\end{tabular}

keseluruhan sistem. Sampling responden yang dituju adalah pegawai dinas di bagian penelitian dan pengembangan, mahasiswa maupun alumni program studi yang terkait dengan teknologi informasi, serta bebas. Tujuannya ialah untuk mengetahui sudah layak atau belum sistem ini dioperasikan dan mudah atau tidak untuk digunakan oleh orang-orang yang masih awam mengenai website. Masing-masing dilakukan pengambilan data dan disajikan dalam bentuk tabel yang kemudian dianalisis agar diperoleh suatu kesimpulan. Adapun rancangan formulir yang digunakan sebagai acuan untuk pengujian perangkat keras maupun perangkat lunak sistem ditunjukkan pada Tabel I.

Pengambilan data yang dilakukan menggunakan kuesioner mengikuti skala Guttman yang menggunakan dua opsi, yaitu “ya” dan “tidak”. Skala Guttman ini memiliki perhitungan khusus untuk menilai jawaban responden dalam bentuk persentase, sehingga dapat diberikan kesimpulan layak atau tidak. Jawaban tersebut diubah menjadi 1 untuk jawaban benar dan 0 untuk jawaban salah dengan memperhitungkan pula nilai error-nya [11]. Adapun dua koefisien yang harus terpenuhi untuk menghitung validitas persentasenya adalah sebagai berikut.

1) Koefisien Reprodusibilitas $\left(K_{r}\right)$ : Koefisien ini digunakan untuk mengetahui jumlah kesalahan yang ada sehingga dapat diketahui nilai tingkat keandalannya. Hasil dikatakan cukup baik apabila memiliki nilai lebih dari atau sama dengan 0,90. Adapun rumus yang digunakan ditunjukkan pada (1).

$$
K_{r}=1-\frac{e}{n}
$$

dengan

$$
\begin{aligned}
& e=\text { jumlah error atau penyimpangan } \\
& n=\text { jumlah butir pertanyaan } \times \text { jumlah responden [12]. }
\end{aligned}
$$

2) Koefisien Skalabilitas $\left(K_{s}\right)$ : Koefisien ini digunakan untuk menilai persentase toleransi penyimpangan yang dikatakan cukup baik apabila memiliki nilai lebih besar atau sama dengan 0,60 [12], seperti ditunjukkan pada (2).

$$
K_{S}=1-\frac{e}{P E}
$$

dengan

$$
\begin{aligned}
& e=\text { jumlah error atau penyimpangan } \\
& P E=\text { jumlah error yang diharapkan }(0,5 \times n) \text { [13] }
\end{aligned}
$$

Dalam analisis hasil akan disampaikan dalam bentuk metode penelitian kualitatif deskriptif yang diuraikan berdasarkan fakta yang sudah didapatkan dari responden dalam bentuk narasi 


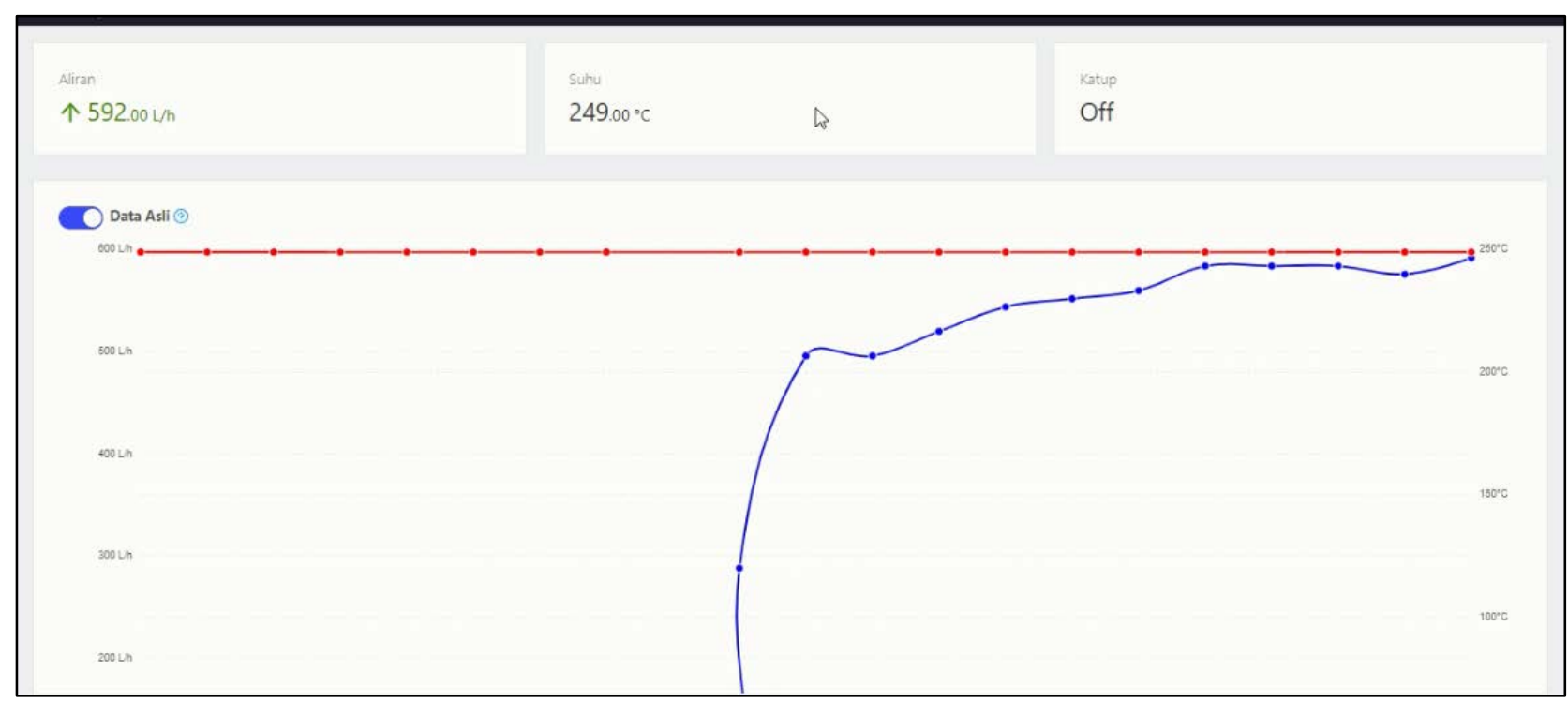

Gbr. 3 Grafik monitoring debit fluida.

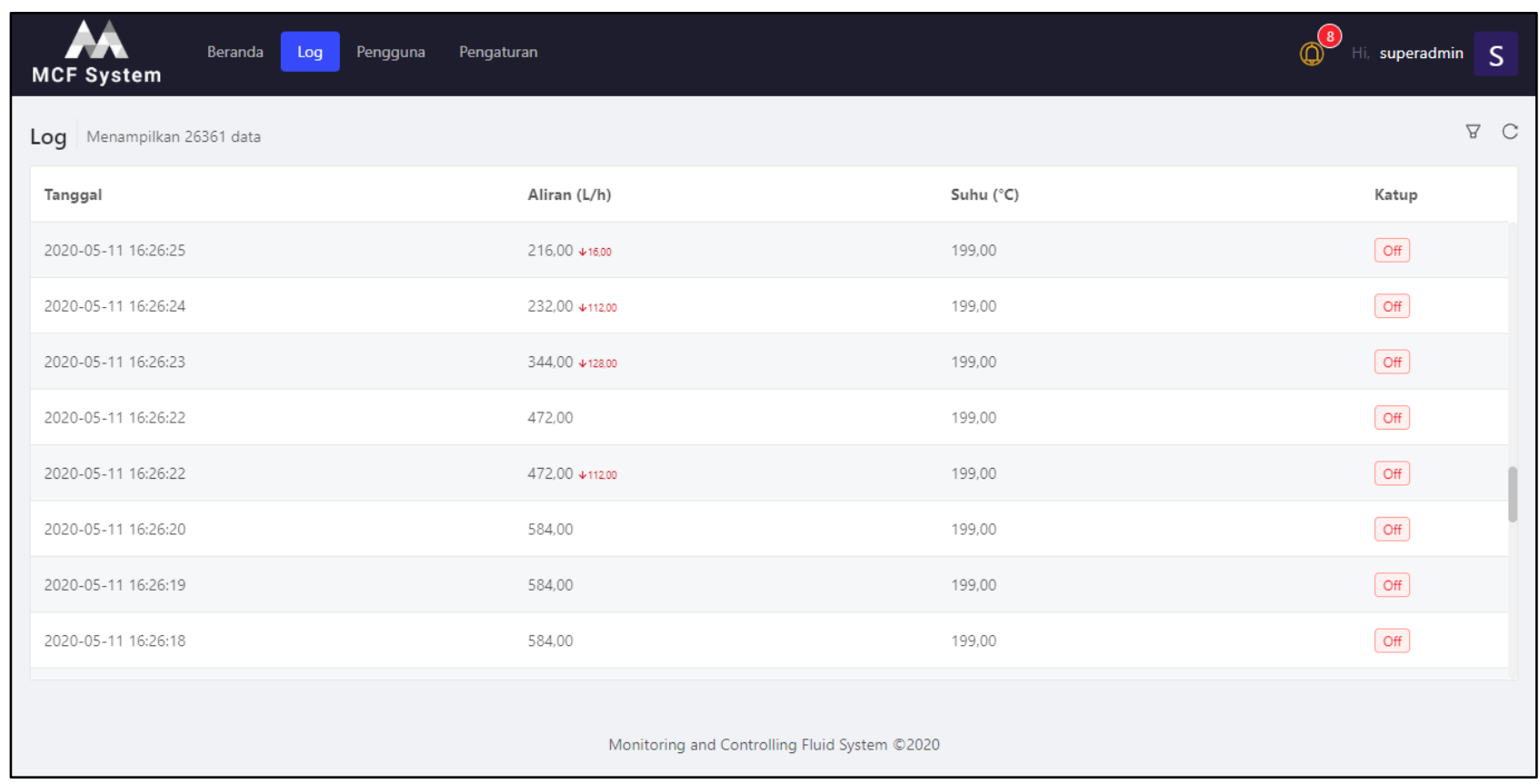

Gbr. 4 Log data debit fluida.

[14], yang juga ditunjang untuk perhitungan validitas sistem terhadap kelayakannya untuk memenuhi blackbox testing.

\section{HASIL DAN PEMBAHASAN}

Pengujian dilakukan pada dua sisi, yaitu perangkat keras yang meliputi sensor YF-S201, katup solenoid, dan ethernet shield, kemudian dilakukan pengujian perangkat lunak, yaitu menu dan fitur yang ada. Penelitian sebelumnya juga membagi menjadi dua bagian pengujian, yakni pengujian perangkat keras dengan perangkat lunak sistem yang menggunakan blackbox testing. Dari metode ini, didapatkan hasil dan analisis secara umum bahwa sistem dapat berjalan dengan baik berdasarkan hasil masukan dan hasil keluaran dari sistem pemantau kendaraan. Selain itu, dengan menggunakan metode ini juga dapat diketahui fungsi yang tidak berjalan dengan benar, antarmuka yang bermasalah, kesalahan dalam mengakses sistem basis data maupun server, bahkan dapat diketahui juga hasil yang didapat sesuai atau tidak dengan perancangan aplikasi tersebut [15].

\section{A. Hasil Pengujian Perangkat Keras}

Pada pengujian ini, katup solenoid diberi tegangan sebesar $12 \mathrm{~V}$ kemudian disambungkan dengan relay $5 \mathrm{~V}$ agar dapat terhubung dan diproses oleh mikrokontroler. Skenario dan hasil pengujian katup solenoid dengan metode blackbox testing sesuai dengan kebutuhan sistem disajikan dalam Tabel II. Adapun skenario dan hasil dari pengujian sensor YF-S201 dengan metode blackbox testing sesuai dengan kebutuhan 
TABEL VII

BLACKBOX TESTING MENU LOG

\begin{tabular}{|c|c|c|c|}
\hline Butir Uji & Hasil yang Diharapkan & $\begin{array}{c}\text { Hasil Sebenarnya } \\
\end{array}$ & Kesimpulan \\
\hline Tampilan log & $\begin{array}{l}\text { Menampilkan tabel riwayat aktivitas } \\
\text { yang dilakukan. }\end{array}$ & $\begin{array}{l}\text { User dapat melihat tabel riwayat } \\
\text { aktivitas yang dilakukan mulai dari } \\
\text { waktu, debit aliran, suhu dan status } \\
\text { katup solenoid. }\end{array}$ & Berhasil \\
\hline Filter aliran & $\begin{array}{l}\text { Menyaring data riwayat aktivitas } \\
\text { aliran yang memuat kata kunci yang } \\
\text { dimasukkan pada field pencarian. }\end{array}$ & $\begin{array}{l}\text { Melakukan dan menampilkan } \\
\text { penyaringan data riwayat aktivitas } \\
\text { aliran yang memuat kata kunci yang } \\
\text { diberikan. }\end{array}$ & Berhasil \\
\hline Filter suhu & $\begin{array}{l}\text { Menyaring data riwayat aktivitas suhu } \\
\text { yang memuat kata kunci yang } \\
\text { dimasukkan pada field pencarian. }\end{array}$ & $\begin{array}{l}\text { Melakukan dan menampilkan } \\
\text { penyaringan data riwayat aktivitas suhu } \\
\text { yang memuat kata kunci yang } \\
\text { diberikan. }\end{array}$ & Berhasil \\
\hline Filter kondisi aliran & $\begin{array}{l}\text { Menyaring data riwayat aktivitas } \\
\text { aliran yang memuat kata kunci yang } \\
\text { dimasukkan pada field pencarian } \\
\text { dengan kondisi operator tertentu. }\end{array}$ & $\begin{array}{l}\text { Melakukan dan menampilkan } \\
\text { penyaringan data riwayat aktivitas } \\
\text { aliran yang memuat kata kunci yang } \\
\text { diberikan dengan kondisi operator } \\
\text { tertentu. }\end{array}$ & Berhasil \\
\hline Filter kondisi suhu & $\begin{array}{l}\text { Menyaring data riwayat aktivitas suhu } \\
\text { yang memuat kata kunci yang } \\
\text { dimasukkan pada field pencarian } \\
\text { dengan kondisi operator tertentu. }\end{array}$ & $\begin{array}{l}\text { Melakukan dan menampilkan } \\
\text { penyaringan data riwayat aktivitas suhu } \\
\text { yang memuat kata kunci yang diberikan } \\
\text { dengan kondisi operator tertentu. }\end{array}$ & Berhasil \\
\hline $\begin{array}{l}\text { Filter dua kondisi } \\
\text { aliran }\end{array}$ & $\begin{array}{l}\text { Menyaring data riwayat aktivitas } \\
\text { aliran yang memuat kata kunci yang } \\
\text { dimasukkan pada field pencarian } \\
\text { dengan dua kondisi operator tertentu. }\end{array}$ & $\begin{array}{l}\text { Melakukan dan menampilkan } \\
\text { penyaringan data riwayat aktivitas suhu } \\
\text { yang memuat kata kunci yang diberikan } \\
\text { dengan dua kondisi operator tertentu. }\end{array}$ & Berhasil \\
\hline $\begin{array}{l}\text { Filter kedua kondisi } \\
\text { suhu }\end{array}$ & $\begin{array}{l}\text { Menyaring data riwayat aktivitas suhu } \\
\text { yang memuat kata kunci yang } \\
\text { dimasukkan pada field pencarian } \\
\text { dengan dua kondisi operator tertentu. }\end{array}$ & $\begin{array}{l}\text { Melakukan dan menampilkan } \\
\text { penyaringan data riwayat aktivitas suhu } \\
\text { yang memuat kata kunci yang diberikan } \\
\text { dengan dua kondisi operator tertentu. }\end{array}$ & Berhasil \\
\hline Filter tanggal aliran & $\begin{array}{l}\text { Menyaring data riwayat aktivitas } \\
\text { aliran berdasarkan tanggal yang } \\
\text { ditentukan. }\end{array}$ & $\begin{array}{l}\text { Melakukan dan menampilkan } \\
\text { penyaringan data riwayat aktivitas } \\
\text { aliran berdasarkan tanggal yang } \\
\text { ditentukan. }\end{array}$ & Berhasil \\
\hline Filter tanggal suhu & $\begin{array}{l}\text { Menyaring data riwayat aktivitas suhu } \\
\text { berdasarkan tanggal yang ditentukan. }\end{array}$ & $\begin{array}{l}\text { Melakukan dan menampilkan } \\
\text { penyaringan data riwayat aktivitas suhu } \\
\text { berdasarkan tanggal yang ditentukan. }\end{array}$ & Berhasil \\
\hline Filter tidak sesuai & $\begin{array}{l}\text { Tidak dapat memunculkan data } \\
\text { apapun. }\end{array}$ & Tabel log menampilkan 0 data. & Berhasil \\
\hline Hapus filter & $\begin{array}{l}\text { Menghapus penyaringan data yang } \\
\text { sebelumnya diaplikasikan. }\end{array}$ & $\begin{array}{l}\text { Menghapus penyaringan data yang } \\
\text { dilakukan sebelumnya dan } \\
\text { mengembalikan ke tampilan log awal. }\end{array}$ & Berhasil \\
\hline Refresh log & $\begin{array}{l}\text { Memuat ulang data riwayat aktivitas } \\
\text { log baik terjadi perubahan maupun } \\
\text { tidak. }\end{array}$ & $\begin{array}{l}\text { Data riwayat aktivitas log dimuat ulang } \\
\text { saat diklik ikon "Refresh". }\end{array}$ & Berhasil \\
\hline
\end{tabular}

sistem disajikan dalam Tabel III, sedangkan skenario dan hasil dari pengujian ethernet shield dengan metode blackbox testing sesuai dengan kebutuhan sistem disajikan dalam Tabel IV.

\section{B. Hasil Pengujian Perangkat Lunak}

Tahap pengujian perangkat lunak ini juga menggunakan metode blackbox testing untuk menguji fungsionalitas sistem tanpa memperhatikan logika dan proses yang dilakukan perangkat, sehingga pengujian ini difokuskan pada nilai masukan dan keluaran dari sistem dengan memberikan nilai yang salah maupun benar. Untuk bagian perangkat lunak digunakan media website sebagai penampil data dan pengendalian untuk perangkat keras yang terintegrasi.
Beberapa butir uji menjabarkan menu login dengan metode blackbox testing, seperti yang ditunjukkan pada Tabel V.

Selanjutnya adalah menu Beranda sebagai fokus utama pemantauan melalui website. Grafik pada menu ini akan berjalan secara real-time, yang dibuktikan dengan adanya waktu yang sesuai dengan kondisi saat sistem dijalankan, seperti pada Gbr. 3. Pengujian menu beranda ini dititikberatkan untuk mengetahui sistem dapat berjalan sesuai dengan skenario yang diharapkan atau tidak, yang diperinci melalui Tabel VI.

Pengujian menu log didasarkan pada butir uji, seperti melihat aktivitas, pencarian filter untuk fluida dan suhu serta kondisi yang diinginkan, dan memuat ulang riwayat. Selain itu, bagian log ini juga memiliki kolom "Tanggal” untuk 
TABEL VIII

BLACKBOX Testing MENu Pengaturan

\begin{tabular}{|c|c|c|c|}
\hline Butir Uji & Hasil yang Diharapkan & $\begin{array}{r}\text { Hasil Sebenarnya } \\
\end{array}$ & Kesimpulan \\
\hline $\begin{array}{l}\text { Pengaturan } \\
\text { utama }\end{array}$ & $\begin{array}{l}\text { Menampilkan pengaturan } \\
\text { utama. }\end{array}$ & User dapat masuk ke pengaturan utama. & Berhasil \\
\hline $\begin{array}{l}\text { Menghidupkan } \\
\text { katup solenoid }\end{array}$ & $\begin{array}{l}\text { Mengeklik button "on" } \\
\text { kemudian klik "Simpan" untuk } \\
\text { menghidupkan katup solenoid. }\end{array}$ & $\begin{array}{l}\text { Dapat mengeklik button “on" dan klik "Simpan” untuk } \\
\text { menghidupkan katup solenoid sehingga status menjadi } \\
\text { "on" juga di beranda maupun log. }\end{array}$ & Berhasil \\
\hline $\begin{array}{l}\text { Mematikan } \\
\text { katup solenoid }\end{array}$ & $\begin{array}{l}\text { Mengeklik button "off" } \\
\text { kemudian klik "Simpan" untuk } \\
\text { mematikan katup solenoid. }\end{array}$ & $\begin{array}{l}\text { Dapat mengeklik button “off” dan klik "Simpan” untuk } \\
\text { mematikan katup solenoid sehingga status menjadi “on” } \\
\text { juga di beranda maupun log. }\end{array}$ & Berhasil \\
\hline $\begin{array}{l}\text { Menghidupkan } \\
\text { notifikasi }\end{array}$ & $\begin{array}{l}\text { Mengeklik button “on" } \\
\text { kemudian klik "Simpan” untuk } \\
\text { menghidupkan notifikasi. }\end{array}$ & $\begin{array}{l}\text { Dapat mengeklik button “on" dan klik "Simpan” untuk } \\
\text { menghidupkan notifikasi sehingga pada bagian notifikasi } \\
\text { akan muncul pemberitahuan bahwa menu Pengaturan } \\
\text { telah diubah. }\end{array}$ & Berhasil \\
\hline $\begin{array}{l}\text { Mematikan } \\
\text { notifikasi }\end{array}$ & $\begin{array}{l}\text { Mengeklik button "off" } \\
\text { kemudian klik "Simpan" untuk } \\
\text { mematikan notifikasi. }\end{array}$ & $\begin{array}{l}\text { Dapat mengeklik button “off” dan klik “Simpan” untuk } \\
\text { mematikan notifikasi sehingga pada bagian notifikasi } \\
\text { akan muncul pemberitahuan bahwa menu Pengaturan } \\
\text { telah diubah. }\end{array}$ & Berhasil \\
\hline $\begin{array}{l}\text { Mengisi } \\
\text { notifikasi suhu }\end{array}$ & $\begin{array}{l}\text { Mengeklik button “on" } \\
\text { kemudian klik "Simpan" untuk } \\
\text { menghidupkan notifikasi suhu } \\
\text { bila mencapai nilai yang telah } \\
\text { ditentukan. }\end{array}$ & $\begin{array}{l}\text { Dapat mengeklik button “on" dan klik "Simpan” untuk } \\
\text { menghidupkan notifikasi nilai suhu yang telah ditentukan } \\
\text { sehingga pada bagian notifikasi akan muncul } \\
\text { pemberitahuan bahwa menu Pengaturan telah diubah. }\end{array}$ & Berhasil \\
\hline $\begin{array}{l}\text { Menghidupkan } \\
\text { suhu buatan } \\
\text { (Pengaturan } \\
\text { Buatan) }\end{array}$ & $\begin{array}{l}\text { Mengeklik button "on" } \\
\text { kemudian klik "Simpan” untuk } \\
\text { menghidupkan suhu buatan. }\end{array}$ & $\begin{array}{l}\text { Dapat mengeklik button "on" dan klik "Simpan” untuk } \\
\text { menghidupkan suhu buatan sehingga pada bagian } \\
\text { notifikasi akan muncul pemberitahuan bahwa menu } \\
\text { Pengaturan telah diubah. }\end{array}$ & Berhasil \\
\hline $\begin{array}{l}\text { Mematikan } \\
\text { suhu buatan } \\
\text { (Pengaturan } \\
\text { Buatan) } \\
\end{array}$ & $\begin{array}{l}\text { Mengeklik button "off" } \\
\text { kemudian klik "Simpan" untuk } \\
\text { mematikan suhu buatan. }\end{array}$ & $\begin{array}{l}\text { Dapat mengeklik button “off” dan klik "Simpan” untuk } \\
\text { mematikan suhu buatan sehingga pada bagian notifikasi } \\
\text { akan muncul pemberitahuan bahwa menu Pengaturan } \\
\text { telah diubah. }\end{array}$ & Berhasil \\
\hline $\begin{array}{l}\text { Mengatur suhu } \\
\text { buatan }\end{array}$ & Mengisi nilai suhu buatan. & $\begin{array}{l}\text { Mengisi nilai suhu buatan kemudian klik “Simpan” } \\
\text { sehingga pada beranda dan log nilai suhu akan tetap } \\
\text { sesuai dengan yang diatur. }\end{array}$ & Berhasil \\
\hline $\begin{array}{l}\text { Klik button } \\
\text { "Simpan" }\end{array}$ & $\begin{array}{l}\text { Akan menyimpan semua } \\
\text { pengaturan. }\end{array}$ & Muncul popup “Berhasil mengubah pengaturan”. & Berhasil \\
\hline
\end{tabular}

memperlihatkan waktu dari kondisi sistem saat dijalankan, sehingga data yang dikirimkan selalu diperbarui. Hal ini juga dapat membuktikan bahwa sistem telah berjalan secara realtime, seperti ditunjukkan pada Gbr. 4. Butir uji pada menu Log didetailkan pada Tabel VII.

Pengujian menu pengaturan didasarkan pada butir uji, seperti pengaturan membuka atau menutupnya katup solenoid, pengaturan terhadap keluarnya notifikasi, dan pengaturan untuk menampilkan suhu standar dalam membuka atau menutupnya pipa tambahan yang terdapat katup solenoid. Pengendalian pada website terhadap katup solenoid dapat dilihat pada Gbr. 5. Butir uji tersebut didetailkan pada Tabel VIII, yang menguji keseluruhan bagian pada menu Pengaturan, baik yang umum maupun buatan.

\section{Analisis Data Responden}

Setelah mendapatkan 137 responden yang menjawab 27 butir pertanyaan melalui Google Form dengan total jawaban sebanyak 3.699, tahapan selanjutnya adalah menentukan layak tidaknya sistem tersebut dioperasikan kepada pihak terkait dengan meninjau tampilan yang telah disediakan menggunakan metode blackbox testing dengan pengambilan skala keputusan menggunakan skala Guttman. Tampilan dan hasil dari skala Guttman terhadap sistem pemantauan dan pengendalian debit fluida berbasis Arduino dan website diperlihatkan pada Gbr. 6 .

Melalui program tersebut, dapat dilihat kalkulasi hasil terakhir untuk koefisien reproducibility, yaitu 0,949, dan koefisien scalability, yaitu 0,897. Kedua koefisien ini berada di atas ambang batas minimum koefisien, sehingga dapat dikatakan sudah layak uji secara smoke testing dan terbukti bahwa sistem dapat digunakan oleh pengguna dengan mudah dan bermanfaat.

\section{KESIMPULAN}

Berdasarkan hasil dan analisis dari blackbox testing terhadap prototipe sistem pemantauan dan pengendalian debit fluida berbasis Arduino dan website, dapat diambil kesimpulan bahwa blackbox testing yang digunakan untuk menguji perangkat lunak menghasilkan 42 status berhasil dan tidak ada yang gagal, sedangkan pengujian yang dilakukan oleh 137 responden dengan 27 pertanyaan menghasilkan koefisien reproducibility sebesar 95\% dan scalability sebesar 90\% pada seluruh fitur yang diuji. Blackbox testing yang dilakukan untuk pengujian perangkat keras mendapat hasil enam status berhasil dan tidak 


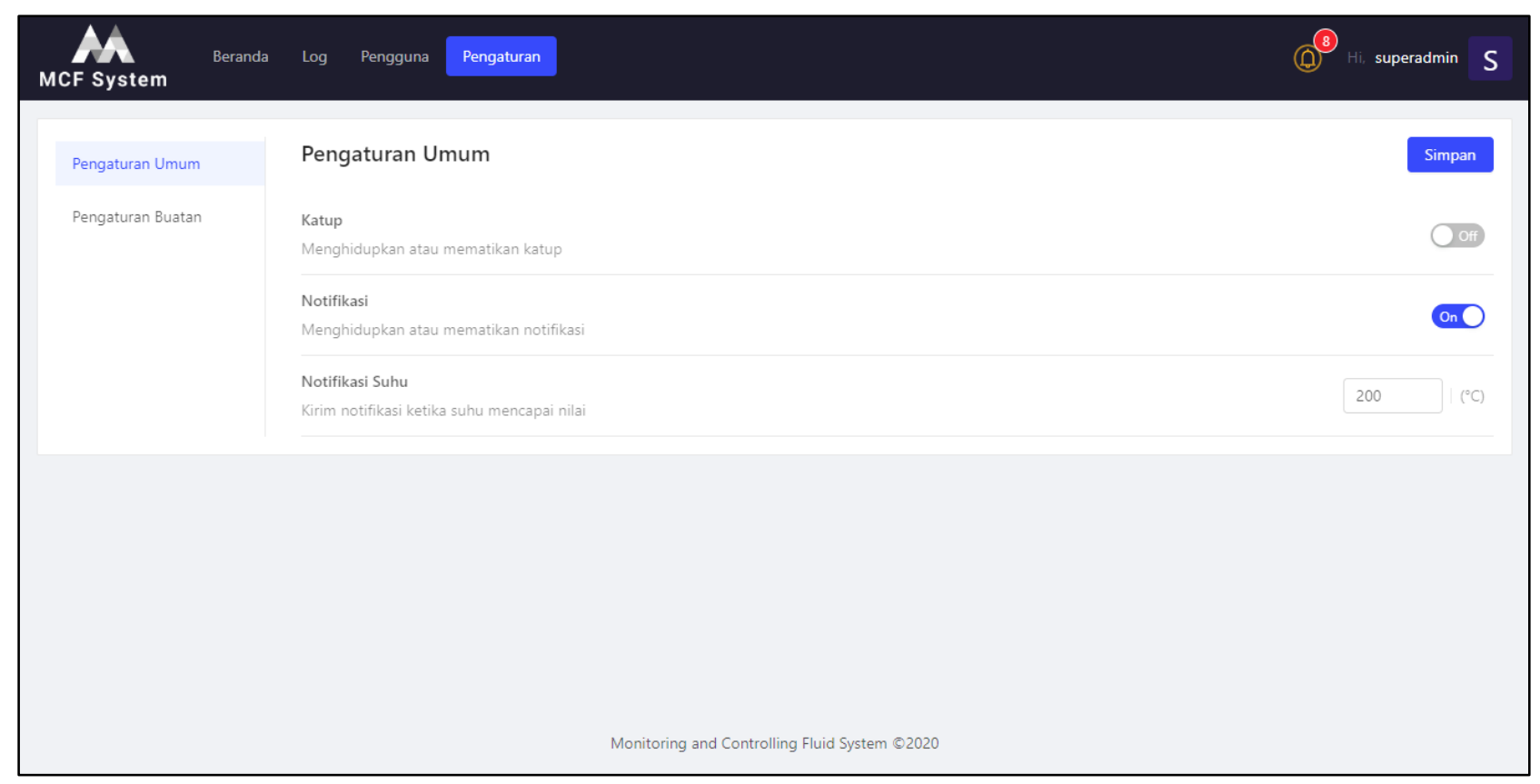

Gbr. 5 Pengaturan kendali katup solenoid.

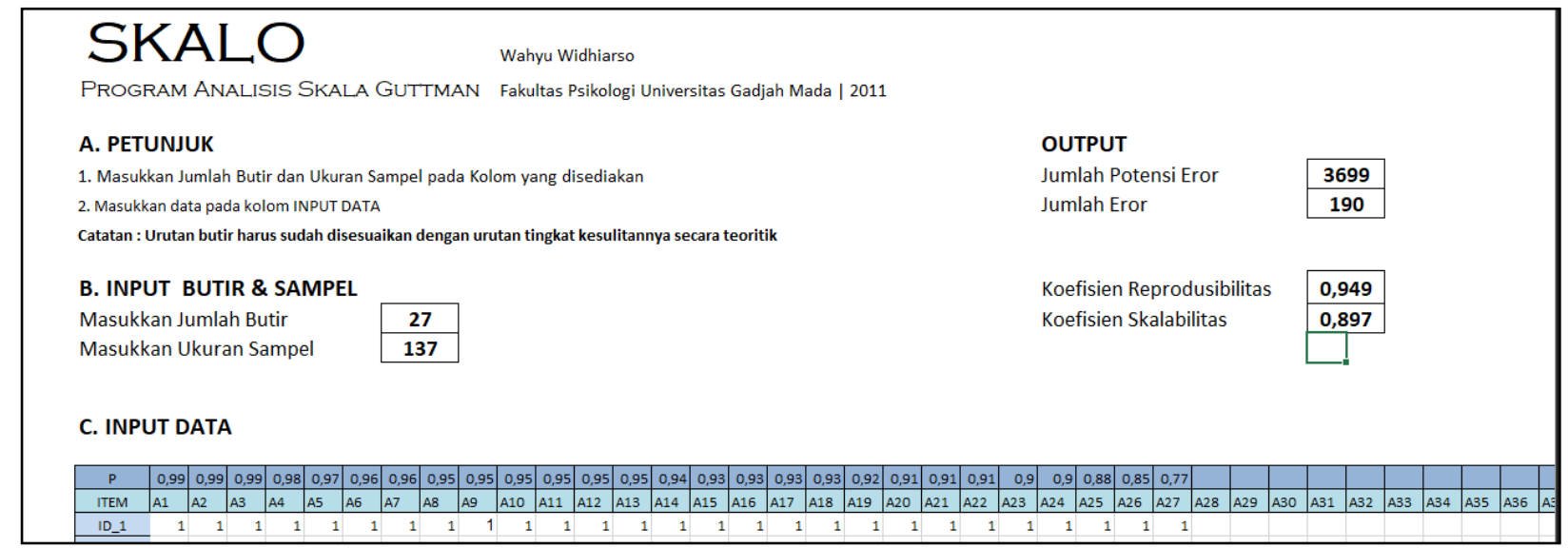

Gbr. 6 Analisis skala Guttman data responden.

ada yang gagal, sehingga perangkat keras tersebut dapat digunakan dan diintegrasikan dengan baik pada sistem yang dirancang. Hasil pengujian menggunakan blackbox testing memberikan pengaruh terhadap fungsional sistem, terutama menggunakan smoke testing yang dapat digunakan oleh pengguna.

Sistem dapat bekerja secara real-time dan dapat mengirim data ke server, yakni Google Compute Engine. Sistem yang dirancang dapat digunakan untuk mempermudah pemantauan debit pada aliran tangki menuju tungku secara daring oleh Admin maupun Super Admin. Sistem yang dirancang dapat digunakan untuk mengendalikan katup dalam kasus penambahan debit fluida secara daring dan jarak jauh oleh Admin maupun Super Admin.

\section{UCAPAN TERIMA KASIH}

Terima kasih disampaikan kepada Departemen Teknik Elektro dan Informatika, Sekolah Vokasi, Universitas Gadjah
Mada, dinas terkait yang telah memberikan kesempatan dan wawasan baru terhadap peneliti, serta responden yang telah menyempatkan waktunya untuk melakukan pengujian.

\section{REFERENSI}

[1] I. Smith, K. Sakamura, A. Furness, R. Ma, Y.-W. Kim, E. Walk, C. Harmon, P. Chartier, P. Guillemin, dan D. Armstrong, "RFID and the Inclusive Model for the Internet of Things," CASAGRAS, West Yorkshire, UK, hal. 1-88, 2009.

[2] A. Junaidi, "Internet of Things, Sejarah, Teknologi dan Penerapannya: Review,” Jurnal Ilmiah Teknologi Informasi Terapan, Vol. I, No. 3, hal. 62-66, Agt. 2015.

[3] O.K. Sulaiman dan A. Widarma, "Sistem Internet of Things (IoT) Berbasis Cloud Computing dalam Campus Area Network," Seminar Nasional Fakultas Teknik UISU, 2017, hal. 9-12.

[4] R. Wiradhana, M.A. Muslim, dan Purwanto, "Sistem Pengendalian Suhu pada Tungku Bakar Menggunakan Kontroler PID,” Jurnal Mahasiswa TEUB, Vol. 1, No. 5, hal. 1-6, 2013.

[5] S. Shahzadi, M. Iqbal, Z.U. Qayyum, dan T. Dagiuklas, "Infrastructure as a Service (IaaS): A Comparative Performance Analysis of Open-Source 
Cloud Platforms," $22^{\text {nd }}$ IEEE International Workshop on Computer Aided Modeling and Design of Communication Links and Networks (CAMAD), 2017, hal. 1-6.

[6] "MODEL: 2019$) \quad$ YF-S201,”
http://www.mantech.co.za/Datasheets/Products/YF-S201_SEA.pdf/, tanggal akses:17-Des-2019.

[7] (2020) "Plastic Water Solenoid Valve - 12V - 1/2" Nominal," [Online], https://media.digikey.com/pdf/Data\%20Sheets/Adafruit\%20PDFs/997_ Web.pdf/, tanggal akses: 10-Jan-2020.

[8] M.W. Habibi, A. Bhawiyuga, dan A. Basuki, "Rancang Bangun IOT Cloud Platform Berbasis Protokol Komunikasi MQTT,” Jurnal Pengembangan Teknologi Informasi dan Ilmu Komputer, Vol. 2, No. 2, hal. 479-485, Feb. 2018.

[9] R.S. Pressman, Software Engineering: A Practitioner's Approach Seventh Edition, New York: McGraw Hills Company, 2010.

[10] N. Balanagu (2011) "Validation: Black Box Testing," [Online], https://sites.google.com/site/testipscenter/validation/Black-box-testing/, tanggal akses: 9-Apr-2020.
[11] P. Dunn-Rankin, G.A. Knezek, S. Wallace, dan S. Zhang, Scaling Method, $2^{\text {nd }}$ ed., New Jersey, USA: Lawrence Erlbaum Associates, Inc., 2004.

[12] F. Rangkuti, Riset Pemasaran, Jakarta, Indonesia: PT. Gramedia Pustaka Utama, 1997.

[13] W. Widhiarso (2011) "Belajar Metodologi Penelitian Kuantitatif: SKALO Program Analisis Skala Guttman,” [Online], http://widhiarso.staff.ugm.ac.id/, tanggal akses: 11-Apr-2020.

[14] A. Anggito dan J. Setiawan, Metodologi Penelitian Kualitatif, E.D. Lestari, Ed., Sukabumi, Indonesia, CV. Jejak, 2018, hal. 9-13.

[15] Rastim, K.M. Lhaksmana, dan D.T. Murdiansyah, “Aplikasi Internet of things Untuk Pengendali dan Pemantau Kendaraan,” e-Proceeding of Engineering, Vol.5, No.1, hal. 1724-1745, Mar. 2018. 